\title{
Particulate matter pollution and the COVID-19 outbreak: results from Italian regions and provinces
}

\author{
Vanessa Bianconi ${ }^{1}$, Paola Bronzo ${ }^{1}$, Maciej Banach ${ }^{2,3}$, Amirhossein Sahebkar ${ }^{4,5}$,
} Massimo R. Mannarino ${ }^{1}$, Matteo Pirro ${ }^{1}$

\author{
${ }^{1}$ Unit of Internal Medicine, Department of Medicine, University of Perugia, Perugia, \\ Italy \\ ${ }^{2}$ Department of Hypertension, WAM University Hospital, Medical University of Lodz, \\ Lodz, Poland \\ ${ }^{3}$ Polish Mothers Memorial Hospital Research Institute (PMMHRI), Lodz, Poland \\ ${ }^{4}$ School of Pharmacy, Mashhad University of Medical Sciences, Mashhad, Iran \\ ${ }^{5}$ Biotechnology Research Centre, Pharmaceutical Technology Institute, \\ Mashhad University of Medical Sciences, Mashhad, Iran
}

Submitted: 4 May 2020

Accepted: 12 May 2020

Arch Med Sci 2020; 16 (5): 985-992

DOI: https://doi.org/10.5114/aoms.2020.95336

Copyright $\odot 2020$ Termedia \& Banach

\begin{abstract}
Introduction: Particulate matter exposure has been associated with the appearance and severity of several diseases, including viral infections. The aim of this study was to investigate whether coronavirus disease 2019 (COVID-19) cases and deaths across Italian regions and provinces in March 2020 were linked to past exposure to fine and coarse particulate matter (namely, $\mathrm{PM}_{2.5}$ and $\mathrm{PM}_{10}$, respectively).

Material and methods: Geographical distributions of COVID-19 cases and deaths (105,792 and 12,428, respectively, up to $31^{\text {st }}$ March 2020), $\mathrm{PM}_{2.5}$ and $\mathrm{PM}_{10}$ exposure, and demographic characteristics were extracted from publicly accessible databases. Adjusted regression models were performed to test the association between particulate matter exposure in different Italian regions and provinces and COVID-19 incidence proportions and death rates. Results: A heterogeneous distribution of COVID-19 cases/deaths and particulate matter exposure was observed in Italy, with the highest numbers in Northern Italy regions and provinces. Independent associations between regional $\mathrm{PM}_{2.5} / \mathrm{PM}_{10}$ exposure and COVID-19 incidence proportion and death rate were observed (COVID-19 incidence proportion: $\beta=0.71, p=0.003$, $\beta=0.61, p=0.031$, respectively; COVID-19 death rate: $\beta=0.68, p=0.004$ and $\beta=0.61, p=0.029$, respectively). Similarly, $\mathrm{PM}_{2.5} / \mathrm{PM}_{10}$ exposures were independently associated with COVID-19 incidence proportion $(\beta=0.26$, $p=0.024$ and $\beta=0.27, p=0.006$, respectively) at the provincial level. The number of days exceeding the provincial limit value of exposure to $\mathrm{PM}_{10}$ $\left(50 \mathrm{\mu g} / \mathrm{m}^{3}\right)$ was also independently associated with the COVID-19 incidence proportion $(\beta=0.30, p=0.008)$.

Conclusions: Exposure to $\mathrm{PM}_{2.5}$ and $\mathrm{PM}_{10}$ is associated with COVID-19 cases and deaths, suggesting that particulate matter pollution may play a role in the COVID-19 outbreak and explain the heterogeneous distribution of COVID-19 in Italian regions and provinces.
\end{abstract}

Key words: deaths, incidence, $\mathrm{PM}_{2.5}, \mathrm{PM}_{10}$, SARS-CoV-2.

\author{
Corresponding author: \\ Matteo Pirro MD, PhD \\ Unit of Internal Medicine \\ University of Perugia \\ Hospital "Santa Maria \\ della Misericordia" \\ Piazzale Menghini 1 \\ 06129 Perugia, Italy \\ Phone: +390755784020 \\ Fax: +39075 5784022 \\ E-mail: matteo.pirro@unipg.it
}




\section{Introduction}

Severe acute respiratory syndrome coronavirus 2 (SARS-CoV-2) is responsible for the outbreak of coronavirus disease 2019 (COVID-19). The COVID-19 numbers are continuously evolving worldwide (about 4 million confirmed cases and 260,000 deaths as of $9^{\text {th }}$ May 2020), and Italy has registered a huge number of COVID-19 cases and deaths as compared to other countries [1]. Lung and systemic inflammation are the most common features of COVID-19, which may lead to multi-organ dysfunction and death [2]. Hence, extensive research in multiple therapeutic areas is rapidly progressing [3, 4]

Airborne particulate matter (PM), also called particle pollution, is considered to be the most relevant component of air pollution [5]. PM is a heterogeneous mixture of solid and liquid, organic and inorganic material suspended in air. The characteristics and sources of ultrafine $\mathrm{PM}\left(\mathrm{PM}_{0.1},<0.1 \mu \mathrm{m}\right)$, fine $\mathrm{PM}\left(\mathrm{PM}_{2.5},<2.5 \mu \mathrm{m}\right)$ and coarse $\mathrm{PM}\left(\mathrm{PM}_{10}\right.$, $<10 \mu \mathrm{m})$ are described elsewhere [5]. Numerous studies have documented the detrimental impact of PM air pollution on several organs [6], particularly airways and lungs [7, 8], although the quality of evidence remains poor in some cases [9]. The existence of a relationship between air pollution, including that from PM, and airborne viral infections has been also proposed [10]. In this regard, an association between air pollution, mainly $\mathrm{PM}_{10}$, and SARS mortality has been reported $[11,12]$. In addition, exposure to ambient $\mathrm{PM}_{25}$ explained a significant percentage of incident cases of influenza [13] and measles in China [14]. Recently, a comprehensive association study found an independent link between six air pollutants, including $\mathrm{PM}_{25}$ and $\mathrm{PM}_{10}$, and the number of COVID-19 confirmed cases in 120 Chinese cities [15]. Also, a significant relationship between long-term exposure to nitrogen dioxide and COVID-19 fatalities has been described [16].

Several mechanisms have been proposed to explain the detrimental association between PM and viral infections: modifications of the respiratory immune response to microbial pathogens $[10,17]$, increased airways vulnerability to respiratory infections [18], exacerbation of multiple comorbidities [19], and additional under-researched mechanisms (e.g. increased viral spread due to attachment of viral particles to PM condensation nuclei) [20].

Based on these premises, on the excess of PM pollution in specific geographical areas in Italy [21], and on the recent debate on the excess of COVID-19 cases and deaths in some areas of Northern Italy as compared to the rest of the country [21-23], we tested the association between PM exposure and COVID-19 cases and deaths in different Italian regions and provinces.

\section{Material and methods}

\section{Data collection}

Data were extracted from publicly accessible databases and stratified by 20 Italian regions and up to 110 provinces (according to availability). The numbers of COVID-19 cases and deaths since $1^{\text {st }}$ March to $31^{\text {st }}$ March 2020 were retrieved from the daily bulletins of the Italian Ministry of Health (available at http://www.salute.gov.it) Data on the population size on $1^{\text {st }}$ January 2019 , the geographical extension of Italian regions and provinces, gender distribution, and the percentage of people aged $\geq 65$ years were collected from the Italian National Statistical Institute (ISTAT) database (available at https://www.istat. it). Mean population exposure to $\mathrm{PM}_{2.5}$ and $\mathrm{PM}_{10}$ and the number of days exceeding the limit value of exposure to $\mathrm{PM}_{10}\left(50 \mathrm{\mu g} / \mathrm{m}^{3}\right)$ in 2017 were extracted from the Italian National Institute for Environmental Protection and Research (ISPRA) databases (available at http://www.isprambiente. gov.it). The mean annual temperatures recorded in 2017 in different Italian provinces were extracted from the ISTAT database, and the mean relative humidity in the last three decades was sourced from an official Italian weather forecast website (www.ilmeteo.it).

\section{Statistical analysis}

SPSS statistical package, release 17.0 (SPSS Inc., Chicago, III) was used for statistical analyses. Base 10 logarithmic (LG) transformation was performed for skewed variables. The COVID-19 incidence proportion was calculated as the ratio between COVID-19 cases recorded in March 2020 and the regional-provincial population sizes per 100,000 inhabitants. The COVID-19-specific death rate was calculated as the ratio between COVID-19-related deaths recorded in March 2020 and the regional population sizes per 100,000 inhabitants (data for provincial death rates were unavailable). ANOVA was used to compare PM measurements across provinces by geographical distribution (North, Centre, South-Islands). Spearman's and Pearson's correlations were used to test the crude associations between the study variables. Multiple linear regression analyses were performed to test whether the exposure to $\mathrm{PM}_{25}$ and $\mathrm{PM}_{10}$ was associated with either COVID-19 incidence proportions across Italian regions and provinces or COVID-19-specific death rates across Italian regions. Variables with a significant crude association with COVID-19 endpoints (incidence proportion and cause-specific death rate) were included as covariates in the multivariable regression analyses; thus, gender distribution across regions and provinces, and territorial extension, 
were always included as independent confounders. In addition to the aforementioned covariates, mean annual temperature and relative humidity were included in the multivariable regression analyses carried out at the provincial level.

\section{Results}

\section{COVID-19 cases and deaths}

Figure 1 shows the Italian trend of COVID-19 cases and deaths since $1^{\text {st }}$ March to $31^{\text {st }}$ March 2020. An uneven distribution of population size, territorial extension, and number of COVID-19 cases and deaths were recorded across Italian regions up to $31^{\text {st }}$ March 2020 (Table I). Lombardia was the Italian region with highest number of COVID-19 cases and deaths, accounting for $41 \%$ and $58 \%$ of the Italian COVID-19 cases and deaths, respectively. The lowest numbers of COVID-19 cases and deaths were recorded in Molise and Basilicata, respectively (Table I). Data on the number of COVID-19 cases stratified by date and Italian provinces are available at www. epicentro.iss.it.

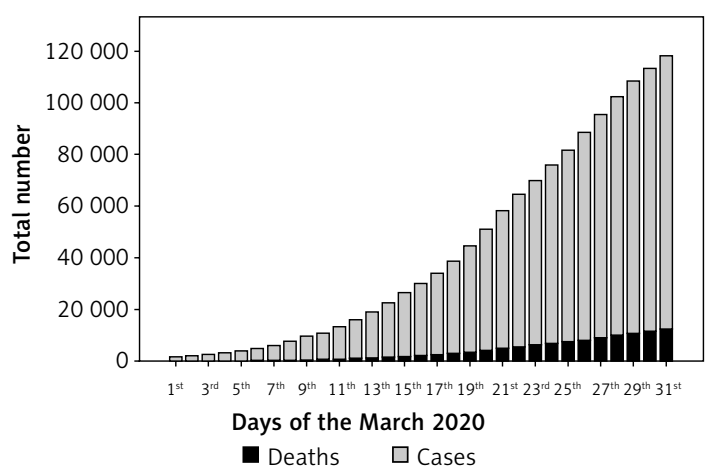

Figure 1. Total number of COVID-19 cases and deaths in Italy from $1^{\text {st }}$ March to $31^{\text {st }}$ March, 2020

\section{Exposure to $\mathrm{PM}_{2,5}$ and $\mathrm{PM}_{10}$ across Italian regions and provinces}

As depicted in Figure $2 \mathrm{~A}$, Lombardia and Veneto were the Italian regions with the highest mean exposure to $\mathrm{PM}_{2.5}$ and $\mathrm{PM}_{10}$, whereas Sardegna and Valle d'Aosta were those with the lowest mean exposure to $\mathrm{PM}_{2.5}$ and $\mathrm{PM}_{10}$, respectively. Figure 2 B shows mean $\mathrm{PM}_{2.5}$ and $\mathrm{PM}_{10}$ exposure

Table I. Demographic characteristics and COVID-19 cases and deaths by geographical region

\begin{tabular}{|c|c|c|c|c|}
\hline Regions & Resident population ( $n$ ) & Territorial extension $\left[\mathrm{km}^{2}\right]$ & Deaths $(n)$ & Total cases $(n)$ \\
\hline Abruzzo & 1311580 & 10831 & 115 & 1401 \\
\hline Basilicata & 562869 & 10073 & 7 & 226 \\
\hline Calabria & 1947131 & 15221 & 36 & 659 \\
\hline Campania & 5801692 & 13670 & 133 & 2092 \\
\hline Emilia-Romagna & 4459477 & 22444 & 1644 & 14074 \\
\hline Friuli-Venezia Giulia & 1215220 & 7932 & 113 & 1593 \\
\hline Lazio & 5879082 & 17231 & 162 & 3095 \\
\hline Liguria & 1550640 & 5416 & 428 & 3416 \\
\hline Lombardia & 10060574 & 23863 & 7199 & 43208 \\
\hline Marche & 1525271 & 9401 & 452 & 3825 \\
\hline Molise & 305617 & 4460 & 9 & 144 \\
\hline Piemonte & 4356406 & 25386 & 854 & 9.301 \\
\hline Puglia & 4029053 & 19540 & 110 & 1803 \\
\hline Sardegna & 1639591 & 24099 & 31 & 722 \\
\hline Sicilia & 4999891 & 25832 & 81 & 1647 \\
\hline Toscana & 3729641 & 22987 & 244 & 4608 \\
\hline Trentino Alto Adige & 1072276 & 13604 & 240 & 3117 \\
\hline Umbria & 882015 & 8464 & 37 & 1078 \\
\hline Valle d'Aosta & 125666 & 3260 & 56 & 628 \\
\hline Veneto & 4905854 & 18345 & 477 & 9155 \\
\hline Total (Italy) & 60359546 & 302068 & 12428 & 105792 \\
\hline
\end{tabular}


A

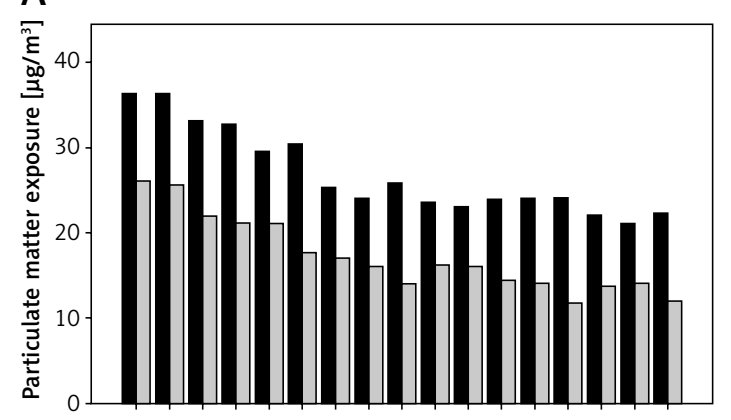

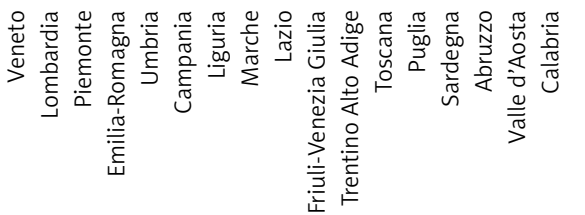

Italian regions

- $\mathrm{PM}_{10} \quad \square \mathrm{PM}_{25}$

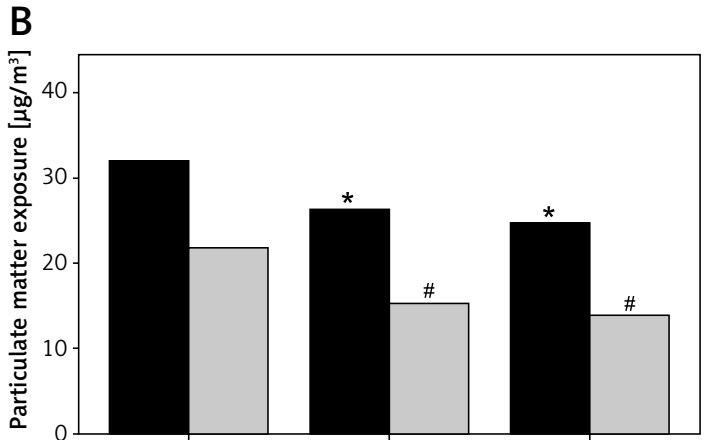

North

Centre

South-Islands

Province geographical positioning

- $\mathrm{PM}_{10} \quad \square \mathrm{PM}_{2.5}$

Figure 2. Mean exposure to particulate matter $\left(P M_{2.5}\right.$ and $\left.P M_{10}\right)$ in Italian regions $(A)$ and provinces stratified according to geographical positioning (i.e. North, Centre, South-Islands) (B). ISPRA PM exposure data were not available for Basilicata and Molise regions, whereas public availability was limited to PM $_{10}$ data for 6 provinces in the Sicilia region. ${ }^{*} P<0.001$ for $\mathrm{PM}_{10}$ comparisons with Northern provinces, ${ }^{*} p<0.001$ for $\mathrm{PM}_{2.5}$ comparisons with Northern provinces

across Italian provinces stratified according to geographical positioning (i.e. North, Centre, South-Islands). Additional data regarding the number of days exceeding the limit value of exposure to $\mathrm{PM}_{10}$ $\left(50 \mu \mathrm{g} / \mathrm{m}^{3}\right)$ in 2017 are reported in Figure 3.

\section{Determinants of COVID-19 incidence proportions and death rate across Italian regions}

Two multiple linear regression models were elaborated including the LG-COVID-19 incidence proportion as the dependent variable and the following independent variables: gender distribution, territorial region extension, and the regional mean annual exposure to $\mathrm{PM}_{2.5}$ and $\mathrm{PM}_{10}$ (Table II). Both $\mathrm{PM}_{2.5}$ and $\mathrm{PM}_{10}$ were associated with COVID-19 incidence proportion irrespective of confounders $(\beta=0.71, p=0.003$ and $\beta=0.61, p=$ 0.031 , respectively). Two additional multiple linear regression models were elaborated including the LG-COVID-19 death rate as the dependent variable and the same independent variables as in the

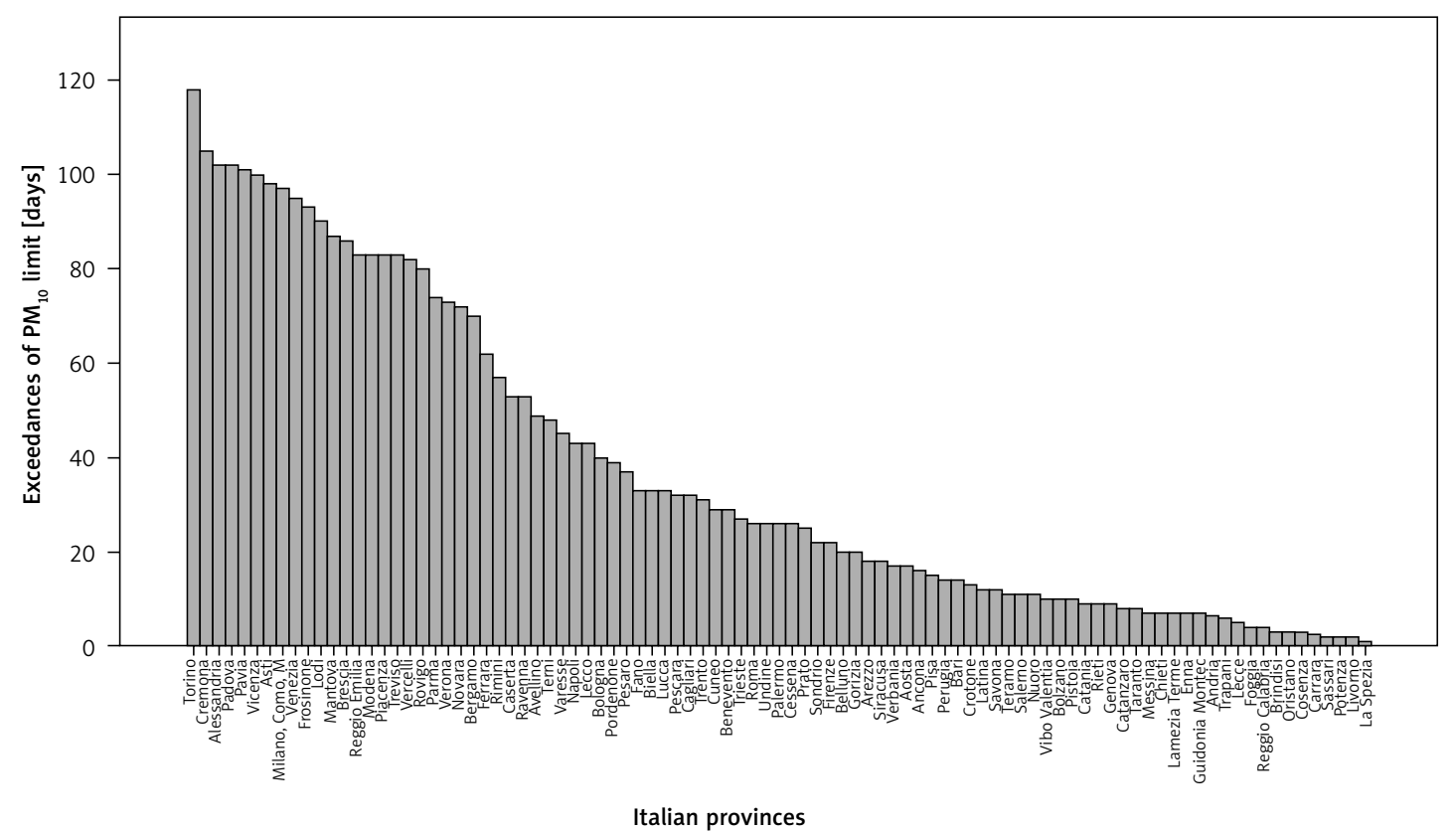

Figure 3. Number of days exceeding the recommended $P M_{10}$ limits $\left(>50 \mu \mathrm{g} / \mathrm{m}^{3}\right)$ in Italian provinces according to ISPRA (2017) 
Table II. Adjusted associations between ISPRA-released data on PM 2.5 and PM $_{10}$ exposure and COVID-19 incidence proportion and death rate

\begin{tabular}{|lccc|}
\hline Pollution measure & Territorial level & $\begin{array}{c}\text { LG-COVID-19 incidence } \\
\text { proportion (adjusted } \beta \text { and } p \text { ) }\end{array}$ & $\begin{array}{c}\text { LG-COVID-19 death rate } \\
\text { (adjusted } \beta \text { ) }\end{array}$ \\
\hline Mean $\mathrm{PM}_{2.5}\left[\mu \mathrm{g} / \mathrm{m}^{3}\right]$ & Regional & $0.71-0.003$ & $0.68-0.004$ \\
\hline Mean $\mathrm{PM}_{10}\left[\mu \mathrm{g} / \mathrm{m}^{3}\right]$ & Regional & $0.61-0.031$ & $0.61-0.029$ \\
\hline Mean $\mathrm{PM}_{2.5}\left[\mu \mathrm{g} / \mathrm{m}^{3}\right]$ & Provincial & $0.26-0.024$ & n.a. \\
\hline Mean $\mathrm{PM}_{10}\left[\mu \mathrm{g} / \mathrm{m}^{3}\right]$ & Provincial & $0.27-0.006$ & n.a. \\
\hline $\mathrm{PM}_{10}>50 \mu \mathrm{g} / \mathrm{m}^{3}[$ days $]$ & Provincial & $0.30-0.008$ & n.a. \\
\hline
\end{tabular}

A

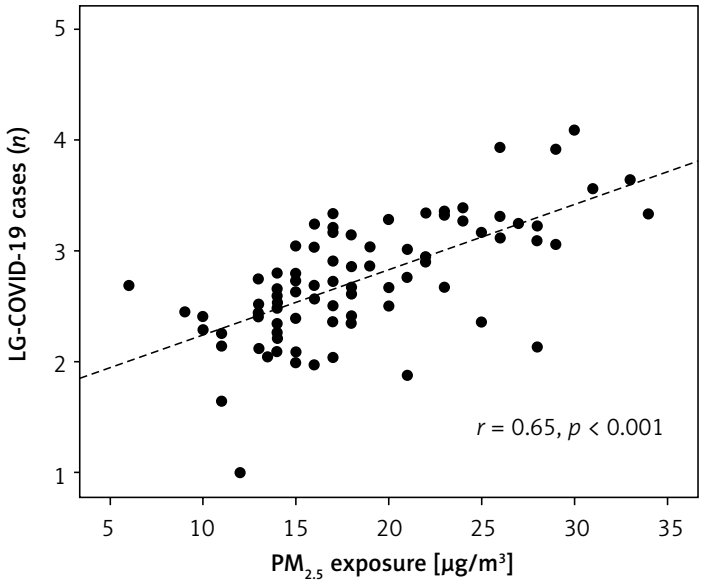

B

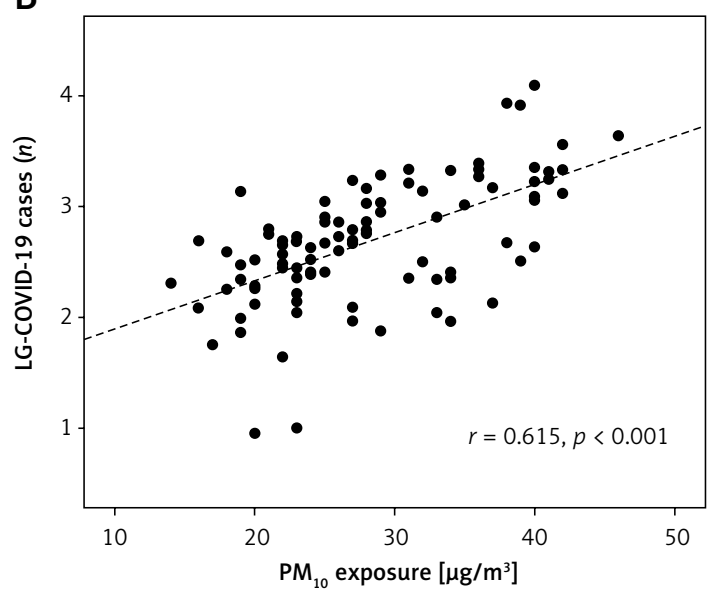

Figure 4. Correlation between the number of COVID-19 cases in Italian provinces and either $\mathrm{PM}_{2.5}(\mathbf{A})$ or $^{\mathrm{PM}} \mathrm{M}_{10}(\mathbf{B})$ exposure

previous regression model (Table II). Again, both indices of PM exposure (i.e. $\mathrm{PM}_{2.5}$ and $\mathrm{PM}_{10}$ ) were independently associated with COVID-19 death rates across Italian regions $(\beta=0.68, p=0.004$ and $\beta=0.61, p=0.029$, respectively).

\section{Determinants of COVID-19 incidence} proportions across Italian provinces

Crude positive correlations between the mean annual exposure to either $\mathrm{PM}_{2.5}$ (available complete data for 81 provinces) or $\mathrm{PM}_{10}$ (available complete data for 97 provinces), and LG-COVID-19 cases are depicted in Figures $4 \mathrm{~A}$ and $\mathrm{B}$, respectively.

Two multiple linear regression models were elaborated including the LG-COVID-19 incidence proportion and the following independent variables: gender distribution, territorial provincial extension, mean annual temperature, relative humidity, and the provincial mean annual exposure to either $\mathrm{PM}_{2.5}$ or $\mathrm{PM}_{10}$ (Table II). Both $\mathrm{PM}_{2.5}$ and $\mathrm{PM}_{10}$ exposures were independently associated with COVID-19 incidence proportion across Italian provinces $(\beta=0.26, p=0.024$ and $\beta=0.27$, $p=0.006$, respectively) (Table II). In the regression model with $\mathrm{PM}_{2.5}$ as an independent variable, both mean annual temperature $(\beta=-0.46, p<0.001)$ and relative humidity $(\beta=0.25, p=0.024)$ were in- dependently associated with COVID-19 incidence proportion. Similar results for annual temperature $(\beta=-0.51, p<0.001)$ and relative humidity $(\beta=$ $0.23, p=0.021$ ) were observed in the $\mathrm{PM}_{10}$ multivariate model.

An additional multiple linear regression analysis in Italian provinces was performed with LGCOVID-19 incidence proportion as the dependent variable and the number of days exceeding the limit value of exposure to $\mathrm{PM}_{10}\left(50 \mathrm{\mu g} / \mathrm{m}^{3}\right)$ as an independent variable along with confounders. Also in this regression model, the index of $\mathrm{PM}_{10}$ exposure was independently associated with COVID-19 incidence proportion ( $\beta=0.30, p=0.008$ ) (Table II).

\section{Discussion}

In this study, exploring the association between past $\mathrm{PM}_{2.5}$ and $\mathrm{PM}_{10}$ and the excess of COVID-19 related features (i.e. cases and deaths) in Italy, two main results emerged. First, an extremely heterogeneous distribution of COVID-19 cases and deaths across Italian regions and provinces was evident. Second, region-stratified and province-stratified exposure to $\mathrm{PM}_{2.5}$ and $\mathrm{PM}_{10}$ was associated with COVID-19 incidence proportion and cause-specific death rate, irrespective of demographic and climatic confounders. 
In the analysis restricted to the Italian data of March 2020, $41 \%$ of COVID-19 cases and $58 \%$ of deaths were observed in the Lombardia region, respectively. Conversely, less than $1 \%$ of all these COVID-19 features were registered cumulatively in the Molise and Basilicata regions. Similarly, an uneven distribution of COVID-19 cases across 104 Italian provinces was evident, with Northern Italy provinces counting the highest numbers and Southern Italy provinces the lowest numbers [22]. Several differential factors might have contributed to the uneven geographical distribution of COVID-19 cases and deaths, including population size and territorial extension, peculiar demographic characteristics, local strategies aimed at diagnosing the viral infection, spatio-temporal start and spread of COVID-19, level of adherence to strict control measures, and additional ones. In this study, we found that both population size and territorial extension (at the provincial level) were associated with COVID-19 cases in a positive $(\beta=0.52, p<0.001)$ and negative $(\beta=-0.32$, $p=0.003)$ fashion, respectively. Thus, in order to minimise their confounding effect on the association between PM exposure and COVID-19 cases and deaths, the COVID-19 incidence proportion and death rate were calculated (accounting for population size), and territorial extension was always included in all multivariate models as a confounder. Our finding of a positive crude association of provincial female gender distribution with COVID-19 incidence proportion (rho $=0.20$, $p=0.03$; result not shown) was unexpected - Italian data from Istituto Superiore di Sanità (ISS) reported a 1.2-fold increased number of COVID-19 cases among men in the "ISS report $-2^{\text {nd }}$ April 2020 - Epidemia COVID-19". However, minimal adjustment (e.g. for only territorial extension) of the reported correlation (gender distribution vs. COVID-19 incidence proportion) abolished completely its statistical significance. In addition, gender differences in the number of COVID-19 cases disappeared in Italy with the progression of the pandemic (data available at www.epicentro.iss.it). Moreover, analysis of international gender-disaggregated data on the crude number of COVID-19 cases shows that male prevalence among COVID-19 cases is not always recurrent; accordingly, there are several countries in which women are more frequently affected by COVID-19 than men and other countries in which COVID-19 cases are equally distributed among men and women (COVID-19 sex-disaggregated data tracker. Global Health 5050. https://globalhealth5050.org/ covid19/. Last data accessed on $9^{\text {th }}$ May 2020). Hence, the influence of gender on COVID-19 incidence proportion remains elusive. An additional finding of the present study is that the association between the proportion of people aged $\geq 65$ years and COVID-19 incidence proportion did not reach statistical significance at the provincial levels ( $r$ o $=0.17, p=0.08$ ); in this case, however, ISS reported that $38 \%$ of COVID-19 cases affected people aged $\geq 70$ years, $17 \%$ those aged $60-70$ years, and the remaining $45 \%$ those aged $<60$ years, thus suggesting that a large number of people less than 65 years old may be affected by COVID-19. Finally, we failed to find associations between the above reported measures (i.e. population size, territorial extension, older age ( $\geq 65$ years), and gender distributions) and COVID-19 death rate; this result, however, should be interpreted in light of the fact that only data for regions (total number \#20) but not for provinces (total number up to \#104) were available. Hence, more comprehensive and simultaneous evaluations of the independent predictivity of multiple measures (i.e. demographic and non-demographic) are necessary and awaited in order to explain the uneven geographical distribution of COVID-19 cases and deaths.

A stimulating debate has recently arisen about the hypothetical link between PM pollution and COVID-19 [21-23]. The discussion is supported by some lines of evidence and theories. First, exposure to PM pollution has been found to be particularly represented in some areas of northern Italy [24, 25], where an excess of COVID-19 cases and deaths has been reported [26]. Second, PM exposure has been causally linked to several organ dysfunctions, mostly involving the respiratory system [6-8, 27-29], the latter being responsible for the severe course of COVID-19 [2, 30]. Third, pathophysiological and epidemiological links between PM exposure and viral infections have been observed [10-20]. Fourth, recent findings of an association between indices of airborne pollution and COVID-19 incidence and fatality have been published [15, 16].

Based on these backgrounds, we wondered whether the extremely heterogeneous distribution of COVID-19 cases and deaths in Italy regions and provinces might be related to differential $\mathrm{PM}_{2.5}$ and $\mathrm{PM}_{10}$ exposure. We showed a significant relationship between all PM exposure indices and both COVID-19 incidence proportion and cause-specific death rate. Importantly, these associations were robust after adjustment for several confounders. In addition, the results were consistent across different indices of PM exposure. Based on these results we may assume that exposure to $P M_{25}$ and $\mathrm{PM}_{10}$ might be considered as possible determinants of COVID-19 onset and severity.

According to published literature, several PM-related mechanistic actions leading to increased vulnerability to SARS-CoV-2 may be proposed, including: 1) dysregulation of early-phase 
immune response leading to reduced immune defences [10, 17]; 2) inflammation and injury of airways $[18,31]$; 3) exacerbation of pre-existing disorders (e.g. chronic obstructive pulmonary disease, asthma, cardiovascular diseases, etc.) [19, 32]; 4) activation of the systemic inflammation cascade [33, 34]; and 5) formation of PM-viral complexes facilitating viral spread [20]. Each of these putative mechanisms linking PM exposure to COVID-19 are highly intriguing although still undemonstrated.

Limitations of this study should be acknowledged. The intrinsic weaknesses of all ecological studies are applicable to this study as well. In this regard, the risk of ecological fallacy leading to biased interpretation of the results may occur due to the possible generalisation of the average measures of exposure to the individual level. Therefore, caution should be exercised when interpreting the results of the present study. Also, potential bias deriving from geographical systematic differences in recording COVID-19-related frequencies or PM exposures may have occurred. However, homogeneous data collection from the Italian Ministry of Health has been performed in all regions and provinces during the COVID-19 outbreak. In addition, multiple indices of PM exposure have been collected. Thus, the latter limitation may have been attenuated. Moreover, the lack of data on potentially important confounders of the association between PM exposure and COVID-19 frequencies should be considered. Thus, a more comprehensive adjustment for additional demographic and disease-related factors is awaited. A further limitation of this study is that $\mathrm{PM}_{2.5}$ and $\mathrm{PM}_{10}$ exposure data are relative to 2017, possibly expressing past exposure to PM pollution. More recent data on these measures were not publicly available. Hence, whether significant changes over time in regional and provincial PM pollution exposure occurring since 2017 until today had an impact on the present results is uncertain.

In conclusion, SARS-CoV-2 infection in Italy affected and caused the death of an extremely high number of subjects, with a heterogeneous distribution across different regions and provinces. We provide data suggesting that the greater diffusion and aggressiveness of COVID-19 might be related, at least in part, to the concomitant past and cumulative exposure to PM pollution. Long-term strategies aimed at protecting people from outdoor PM pollution are eagerly awaited, along with the development of specific and effective therapies and vaccines $[3,35]$.

\section{Acknowledgments}

The authors thank Mr. Pasquale Bronzo for helping in the collection of COVID-19 data.

\section{Conflict of interest}

The authors declare no conflict of interest.

\section{References}

1. Coronavirus disease 2019 (COVID-19) Situation Report - 79. http://www.who.int. Accessed on May $9^{\text {th }} 2020$.

2. Chen T, Wu D, Chen H, et al. Clinical characteristics of 113 deceased patients with coronavirus disease 2019: retrospective study. BMJ 2020; 368: m1091.

3. Borgio J, Alsuwat H, Al Otaibi W, et al. State-of-the-art tools unveil potent drug targets amongst clinically approved drugs to inhibit helicase in SARS-CoV-2. Arch Med Sci 2020; 16: 508-18.

4. Reiner Ž, Hatamipour M, Banach M, et al. Statins and the COVID-19 main protease: in silico evidence on direct interaction. Arch Med Sci 2020; 16: 490-6.

5. Kim KH, Kabir E, Kabir S. A review on the human health impact of airborne particulate matter. Environ Int 2015; 74: 136-3.

6. Schraufnagel DE, Balmes JR, Cowl CT, et al. Air pollution and noncommunicable diseases: a review by the forum of International Respiratory Societies' Environmental Committee, Part 2: air pollution and organ systems. Chest 2019; 155: 417-26.

7. Horne BD, Joy EA, Hofmann MG, et al. Short-term elevation of fine particulate matter air pollution and acute lower respiratory infection. Am J Respir Crit Care Med 2018; 198: 759-66.

8. Leikauf GD, Kim SH, Jang AS. Mechanisms of ultrafine particle-induced respiratory health effects. Exp Mol Med 2020; 52: 329-37.

9. Burney P, Amaral AFS. Air pollution and chronic airway disease: is the evidence always clear? Lancet 2019; 394: 2198-200.

10. Ciencewicki J, Jaspers I. Air pollution and respiratory viral infection. Inhal Toxicol 2007; 19: 1135-46.

11. Cui Y, Zhang ZF, Froines J, et al. Air pollution and case fatality of SARS in the People's Republic of China: an ecologic study. Environ Health 2003; 2: 15.

12. Kan HD, Chen BH, Fu CW, Yu SZ, Mu LN. Relationship between ambient air pollution and daily mortality of SARS in Beijing. Biomed Environ Sci 2005; 18: 1-4.

13. Chen G, Zhang W, Li S, et al. The impact of ambient fine particles on influenza transmission and the modification effects of temperature in China: a multi-city study. Environ Int 2017; 98: 82-8.

14. Chen G, Zhang W, Li S, Williams G, Liu C, Morgan GG. Is short-term exposure to ambient fine particles associated with measles incidence in China? A multi-city study. Environ Res 2017; 156: 306-11.

15. Zhu Y, Xie J, Huang F, Cao L. Association between shortterm exposure to air pollution and COVID-19 infection: evidence from China. Sci Total Environ 2020; 727 : 138704.

16. Ogen Y. Assessing nitrogen dioxide (NO2) levels as a contributing factor to coronavirus (COVID-19) fatality. Sci Total Environ 2020; 726: 138605.

17. Bauer RN, Diaz-Sanchez D, Jaspers I. Effects of air pollutants on innate immunity: the role of Toll-like receptors and nucleotide-binding oligomerization domain-like receptors. J Allergy Clin Immunol 2012; 129: 14-24.

18. Brugha R, Grigg J. Urban air pollution and respiratory infections. Paediatr Respir Rev 2014; 15: 194-9.

19. Zieliński M, Gąsior M, Jastrzębski D, Desperak A, Ziora D. Influence of particulate matter air pollution on ex- 
acerbation of chronic obstructive pulmonary disease depending on aerodynamic diameter and the time of exposure in the selected population with coexistent cardiovascular diseases. Adv Respir Med 2018; 86: 227-33.

20. Lee GI, Saravia J, You D, Shrestha B, Jaligama S, Hebert VY. Exposure to combustion generated environmentally persistent free radicals enhances severity of influenza virus infection. Part Fibre Toxicol 2014; 11: 57.

21. Conticini E, Frediani B, Caro D. Can atmospheric pollution be considered a co-factor in extremely high level of SARS-CoV-2 lethality in Northern Italy? Environ Pollut 2020; 261: 114465 .

22. Vetter P, Eckerle I, Kaiser L. Covid-19: a puzzle with many missing pieces. BMJ 2020; 368: m627.

23. Bianchi F, Cibella F. Air pollution and Covid19: how to compose the puzzle. BMJ 2020; 368: m627.

24. L'epidemiologia per la sanità pubblica. Istituto Superiore di Sanità. Coronavirus. http://www.epicentro.iss.it. Accessed 8 April 2020

25. Dossier di Legambiente. Mal'aria di città 2020. 23 gennaio 2020. http://www.legambiente.it/malaria-di-citta. Accessed 8 April 2020.

26. COVID-19. Situazione in Italia. Ministero della Salute. http://www.salute.gov.it. Accessed 8 April 2020

27. Yoda Y, Takagi H, Wakamatsu J, et al. Stronger association between particulate air pollution and pulmonary function among healthy students in fall than in spring. Sci Total Environ 2019; 675: 483-9.

28. Chen C, Li C, Li Y, et al. Short-term effects of ambient air pollution exposure on lung function: a longitudinal study among healthy primary school children in China. Sci Total Environ 2018; 645: 1014-20.

29. Zhu X, Zhao P, Lu Y, et al. Potential injurious effects of the fine particulate PM2.5 on the progression of atherosclerosis in apoE-deficient mice by activating platelets and leukocytes. Arch Med Sci 2019; 15: 250-61.

30. Bhatraju PK, Ghassemieh BJ, Nichols M, et al. Covid-19 in critically ill patients in the Seattle Region - case series. N Engl J Med 2020. Mar 30. doi: 10.1056/ NEJMoa2004500.

31. Hazar A, Gundogus B. Assessment of inflammatory markers, disease severity and comorbidities in very elderly patients with acute respiratory diseases. Arch Med Sci 2020. doi:10.5114/aoms.2020.94495.

32. Katsiki N, Banach M, Mikhailidis D. Lipid-lowering therapy and renin-angiotensin-aldosterone system inhibitors in the era of the COVID-19 pandemic. Arch Med Sci 2020; 16: 485-9.

33. Tsai DH, Riediker M, Berchet A, et al. Effects of shortand long-term exposures to particulate matter on inflammatory marker levels in the general population. Environ Sci Pollut Res Int 2019; 26: 19697-704.

34. Schillaci G, Pirro M. C-reactive protein in hypertension clinical significance and predictive value. Nutr Metab Cardiovasc Dis 2006; 16: 500-8.

35. Callaway E. The race for coronavirus vaccines: a graphical guide. Nature 2020; 580: 576-77. 